\title{
Developing Schemas for Assessing Social Competences among Unskilled Young People
}

\author{
Vibe Aarkrog*and Bjarne Wahlgren \\ DPU/ Aarhus Universitet, Tuborgvej 164, 2400 København NV
}

Received: 10.08.2016; Accepted: 09.02.2017; Published: 26.04.2017

\begin{abstract}
Social competences are crucial parts of vocational education and training (VET) competences. As part of a development project preparing unskilled young people for VET, an action research project was conducted with the aim of developing a schema for assessing and grading social competences. The development included defining the social competences as well as three levels for assessing these competences. The schema was developed in cooperation with the assessors, i.e., representatives from workplaces, municipal youth guidance centres, and VET colleges. There were two main findings. First, the definitions of the competences and the levels for assessing the competences are related to the context in which the competences should be developed. Second, even though the definitions should be related to the specific contexts, to be manageable they should not be too elaborate. The aim of the project being to develop a schema that practitioners in general can use for assessing young peoples' social competences in relation to work-based training, the study concludes that further research is needed to clarify whether the schema can be used without instruction or training.
\end{abstract}

Keywords: VET, Vocational Education and Training, Assessment, Social Competence, Workplace-based Training, Young Unskilled People, Action Research

\footnotetext{
${ }^{*}$ Corresponding author: viaa@edu.au.dk
}

ISSN: 2197-8646

http://www.ijrvet.net 


\section{Introduction}

In educational policy and educational research competence has been a vital concept for the last twenty years. At a policy level OECD has defined nine key competences within the following three categories: 'using tools interactively', 'interacting in heterogeneous groups' and 'acting autonomously' (OECD, 2005). In a European lifelong learning context, eight competences have been outlined: 'communication in mother tongue, communication in foreign languages', 'mathematical and technological competence', 'digital competence', 'learning to learn', 'social competence', 'innovative competence' and 'cultural awareness' (European Communities, 2007).

In relation to the labour market and to vocational education and training, CEDEFOP has analysed the need for competences. One of the key conclusions from this analysis is:

Social and personal competences are especially important in assessments for management positions, in promotion and succession planning, and with employees who have direct client contact. Overall, notably social competences have become more significant in firms' employee assessments over the past few years (CEDEFOP, 2014, pp. 19-20).

Despite the great political interest in key competences, learning in informal and nonformal settings, and the need for assessing prior learning, only limited research have been conducted about assessing competences obtained in informal settings. In this article we focus on assessment of social competences. Social competences, which will be defined below, constitute a central element in the total competence-landscape as well as in workplace-based learning and vocational education and training (VET). Focusing on social competence in the learning process includes assessing social competence which requires adequate assessment methods to be developed.

Below we describe how methods for assessing social competences were developed in an action research project. The project was related to an ongoing programme, 'Job with an educational perspective', the aim of which was to motivate and qualify unskilled young people to enrol in a VET programme via six months of work-based training. The young people's work experience is obtained within trades and industries where they are able to visualize themselves as future employees, e.g. as assistant chefs, kindergarten assistants, shop assistants, or car mechanics. In order to encourage the young people's participation in education, three dialogue meetings were held with the young people over the course of the training period. The aim of these dialogue meetings was to assess the young people's technical and social competences. The idea is that explaining to the young people how their competences are developing through the work-based training will encourage them for improving their performance in the workplace and eventually for enrolling in a VET programme. In order to secure a systematic and encouraging assessment the dialogues should be based on filling out schemas for assessing technical and social competences.

A schema is a tool for assessing competences. In the left column of the schema the various competences are listed vertically; horizontally three competence levels are listed. The practitioners fill out the schema based on assessing at which level the young person 
performs in relation to each of the competences. The aim of the action research project was to develop schemas that are useful for the practitioners. A schema was drafted for the technical competences for each of the trades and industries whereas the schema for the social competences should be applicable across the various industries and trades. In this article we solely focus on the development of the schema for assessing the young persons' social competences.

\section{The Concept of 'Competence'}

To assess a competence it is necessary to have a precise and comprehensive definition of the concept of competence. The meaning of 'competence' has been discussed within a wide variety of contexts, applying different theoretical approaches, including behaviouristic, generic, and cognitive approaches (Mulder, Weigel, \& Collins, 2007, pp. 69-70). Eraut defines competence as 'the ability to perform the task and the roles required to the expected standard', and adds that competence is always related to a specific context, a particular job or category of job. However, a person does not only possess specific competences. A person possesses a capability, defined as 'everything a person can think or do, given an appropriate context for demonstration of it' (Eraut, 1998, p. 135). Ellström defines the concept in a workplace setting as 'the capacity of an individual to successfully handle certain situations or complete a certain task or job' (Ellström \& Koch, 2008, p. $6)$. Mulder defines competence as the capability to reach specific achievements. Furthermore, he distinguishes between competences and competencies. Competencies are capabilities, capacities, or potentials and can be understood as characteristics of persons (Mulder, 2001, p. 152) while competence is the integrated set of capabilities (or competencies), consisting of knowledge, skills, and attitudes, enabling the person to function effectively in a particular profession, organization, job, role, and situation (Mulder, Gulikers, Biemans, \& Wesselink, 2009, p. 757). We agree with Mulder; however in this article we merely use the concept of competence.

Mulder et al. analyse the use of the concept of competence in vocational education and training in a European context. They conclude that "assessment of competences, especially in work situations, is a labour-intensive and time-consuming exercise" and warn against "competence being formulated in terms that are too general, which means that they have no discriminative power in assessments" (pp. 81-82).

Under the headline 'What Is Competence?' Le Deist and Winterton analyse the use of the concept in the USA, the UK, France, and Germany based on a number of research studies. Not surprisingly, they state that the approach to the concept is multi-dimensional and holistic. Based on their analysis, they construct a typology of competence that should be useful in a vocational context. This typology consists of cognitive competences, functional competences, social competences, and meta-competences (Le Deist \& Winterton, 2007, p. 38).

In line with the considerations above, we define competence as the ability to perform required tasks and roles to the expected standard in a specific context. 
As stated above, in this article we focus on social competences, leading to the question: what is meant by social competence?

\section{The Concept of 'Social Competence'}

A literature study concerning the definition of the concept of social competence shows that the concept can be defined and categorized in various ways.

In the typology of competence mentioned above, social competence is defined as "the willingness and ability to experience and shape relationships, to identify and understand benefits and tensions, and to interact with others in a rational and conscientious way, including the development of social responsibility and solidarity" (Le Deist \& Winterton, 2007, p. 38).

In the Handbook of Social and Emotional Learning, social and emotional competences have been divided into five competences: 'self-awareness', 'self-management', 'social awareness', 'relational skills', and 'decision making'. Furthermore, six tools have been outlined for assessing social and emotional competences within formal educational settings (Denham, 2015, pp. 287-293).

In the Handbook of Competence and Motivation, social competences related to work are listed as 'enterprising', 'social interest', 'extraversion', 'social potency', and 'wellbeing'. The concepts are not elaborated in relation to the work situation, and, under the headline 'assessment', the Handbook summarizes that "the research on the personality determinants of work competences has not made much theoretical progress" (Kanfer \& Ackerman, 2005, pp. 342-343).

In a study in the health sector about assessment of 'communication' in relation to physician-patient communication, this competence was divided into seven sub-competences: 'establishes support', 'opens discussion', 'gathers information', 'understands patient's perspective of illness', 'shares information', 'reaches agreement on problems and plans', and 'provides closure'. These competences were further divided into sub-sub-competences; e.g. the competence 'shares information' was divided into 'uses language patient can understand', 'checks for understanding', and 'encourages questions'. Apart from being an example of rather detailed descriptions the study shows the need to relate the definitions closely to the specific context (Schirmer et al., 2005, p. 185).

In a study similar to the one described in this article, young people's competences were divided into social competences, personal competences, and methodological competences. Social competence was divided into three sub-competences: 'ability to cooperate', 'ability to face conflicts', and 'ability to communicate' (Frey, Balzer, \& Ruppert, 2014, pp. 5-7).

In a literature study seeking to clarify the concept of 'social competence', the authors conclude that "we did not find any instruments in the literature which were suitable for measuring social competence as an educational goal in the broadest sense.... What is considered to be socially competent depends on the context" (Dam \& Volman, 2007, pp. 293-294). 
Based on the studies above, we conclude that essential and recurring elements in social competences are communication, cooperation, and social responsibility. We have analysed how these competences feature in the learning outcome descriptions in the Danish national curricula for VET programmes (see Undervisnings Ministeriet, 2015). Learning outcome descriptions were studied for four VET programmes relevant to the work experience of the participating young people: the programmes for 'car mechanic', 'chef', 'sales assistant', and 'social and healthcare assistant'. Based on the analysis of the four learning outcome descriptions, the research project has focused on developing five categories of social competence, each of them divided into sub-competences. Below, these categories of competence are defined as they were in the final draft of the schema.

Social competence in a workplace setting is the ability to perform social tasks and roles in relation to:

1. Communication, meaning to listen to others, to express oneself clearly, and to signal positivity, including the following sub-competences:

a) Is able to receive feedback from manager on one's job performance and demonstrate the ability to give feedback.

b) Is able to receive feedback from colleagues on job performance and demonstrate the ability to give feedback.

c) Is able to listen to and speak with users (e.g. customers/ citizens/children/parents).

2. Cooperation, meaning to participate in social relations in order to realize own and others' needs, including the following sub-competences:

a) Is able to work in accordance with the supervisor's guidelines.

b) Is able to cooperate with colleagues in performing tasks.

c) Is able to participate in the workplace community.

3. Responsibility, meaning to take responsibility in relation to the job and the tasks involved, including the following sub-competences:

a) Is able to meet on time.

b) Is able to meet standards of reliability.

c) Is able to complete tasks and do not leave a task half-done.

4. Independence, meaning to manage and accomplish work tasks based on own experience and obtained knowledge, including the following sub-competences:

a) Is able to work independently based on instructions and guidance.

b) Is able to perform based on own strengths and weaknesses.

c) Is able to take initiatives in relation to solving tasks. 
5. Social understanding, meaning understanding different ways of performing and behaving, including the following sub-competences:

a) Is able to accept that there are different ways to act and perform.

b) Is able to accept that others can have different attitudes and values.

The definitions and elaborations of the competences should meet the following four requirements:

1. They should be useful for clarifying the development of the young person's competences over time.

2. They should be immediately understandable, relevant, and applicable for the assessors (i.e. the representatives from the workplaces, from the municipal guidance centres, and from the VET colleges), and they should be useful for assessing young unskilled workers. 'Immediately' means that the assessors should be able to use the schema without previous training.

3. They should ensure the validity and reliability of the assessment: the assessors should have a mutual understanding of the meaning of the competences. The assessments should cover the young person's abilities and they should not depend on the individual assessor.

\section{Assessment of Competence}

The principles and methods for assessing competence are not new (Walklin, 1991). Assessment has been discussed in relation to teaching and the teacher's role (Klenowski \& Wyatt-Smith, 2014) and, more specifically, in relation to higher education (Boud \& Falchikov, 2007). In a vocational and adult learning context, competence assessment has been analysed in a critical perspective (Eccleston, 2010). Most of the literature has focused on assessment in relation to education and training programmes. Reviewing articles published in the journal 'Assessment in Education: Principles, Policy and Practice' within the last five years clearly illustrates this tendency. Almost all the articles deal with assessment in relation to learning outcomes from school-based education. Moreover, the focus is on assessing 'knowledge' and 'skills' rather than 'competences', knowledge and skills being the concepts used in the curricula of the educational programmes. An example from one of the few articles about vocational education and training illustrates this tendency:

During the skills demonstration, the student carries out practical tasks in a workplace or at an educational institution or in another working life situation and thus demonstrates how well he or she has attained the goals and the vocational skills required in working life. The content of the demonstration has to correspond to the national requirements of qualification (core curricula) (Räisänen \& Räkköläinen, 2014, p. 113). 
A review on clinical competence assessment in nursing concludes that 'some assessment strategies have been developed and tested'. The reported strategies are tests, self-assessment instruments and portfolios related to the clinical practice (Yanhua \& Watson, 2011, p. 835). Analysing the concept of nurses' holistic competences, a study concludes that assessment of nurse competences should take place in a natural or near natural setting required for the job and must be based on actions; furthermore that written assessment instruments only tell part of the story (namely the amount of knowledge) (Garside \& Nhemachena, 2013, p. 544). A systematic review on competence assessment of 'procedural skills' in the health sector concludes that 'simulators' are valuable for continuous assessment (Ekkelenkamp, Kock, de Man, \& Kuipers, 2016).

Validating and assessing non-formal and informal learning has been highlighted as a consequence of the increasing interest for learning outside the classroom. The CEDEFOP study, mentioned above, includes mapping and analysis of the use of validation instruments for competence assessment in European companies. Based on data from more than 400 companies, the study informs about the different assessment methods used in the companies, concluding that, in general, competence assessment has become more important and that an increasing number of companies have improved and developed their assessment tools (CEDEFOP, 2014, p. 48-58). In a follow-up report from CEDEFOP, six "tools for extracting evidence" have been described: tests and examinations, dialogue, declarative methods, observations, simulations, and evidence extracted from practice (CEDEFOP, 2015, pp. 46-49). Only a minor part of the first report discusses how to ensure quality in the assessment procedure, and none of the reports address the problems related to assessing competences.

The interest in non-formal and informal learning has entailed a focus on the assessment of prior learning, which means assessment of the sum of all the individual's competences. Assessment of prior learning and the associated difficulties have been analysed and described in the research literature. Most of this literature deals with the organizational process (Harris, Breier, \& Wihak, 2011) and the various ways of validating prior learning (Halttunen, Koivisto, \& Billet, 2014). Only few research-based results concern the challenges related to the assessment processes authors (Aarkrog \& Wahlgren, 2015).

Competence acquisition outside the classroom has been described in some studies. These studies mainly deal with the learning process and are less concerned with the problems associated with the assessment process. The themes concentrate on the acquisition of competences outside the formal educational system, e.g. in the workplace (Zegwaard, Coll, \& Hodges, 2003), as part of in-service training (Alqiawi \& Ezzeldin, 2015), in relation to teachers' professional development (Dumitriu, Dumitriu, \& Timofti, 2014), or as a particular teaching method in a university context (Bezanilla et al., 2014).

Much research has been conducted in relation to assessing knowledge, skills, and competences obtained in formal education. However, there has been little research on the assessment process in relation to social competences outside the classroom. Thus there seems to be a need for developing methods that can assess the social competences obtained through performing in real-world workplace situations.

As a consequence, in this article we focus on the assessment of social competences from 
a workplace perspective. We focus on developing an instrument (a schema) which can be used by non-professional assessors to assess competences developed in a workplace context. The research question "How can social competences be assessed in a workplace setting?" includes two sub-research questions:

- How can social competences be defined in a workplace setting?

- How can social competences be graded with a high degree of validity and reliability?

\section{The Research Method}

As stated above the aim of the research project was to develop a method for assessing social competences that would be useful for the practitioners, i.e. assessors of social competences in relation to work performance. The development of the schema included definitions of the content of social competences as well as of the levels of the competences. In order to secure that the schema would be useful for the assessors, the development should be based on a dialogue with the assessors. Therefore the project was conducted as an action research project, in which the researchers and the assessors met regularly to develop, try out, and revise the content of the method (Cohen, Manion, \& Morrison, 2011, p. 18). The underlying idea was that the assessors - together and in dialogue with the researchers - 'produce theory through a reflective examination of their practice, thus simultaneously achieving progress in their practice' (Papastephanou, 2014, p. 178). Using a concept from Donald Schön the assessors were 'reflective practitioners' in the project (Schön, 1983) and reflected continuously on the way they used the assessment instrument.

During the research period, three versions of schema for assessing social competences were drafted, tried out, and revised, concluding in a final version in spring 2016. The development of the schema included the following activities:

1. Meetings with the assessors in order to discuss their understandings of the social competences as well as of the different levels of the social competences.

2. The assessors tested the schema during their dialogues with the young people. The researchers made observations of selected dialogues.

3. The researchers interviewed the assessors about their experiences with employing the schema.

4. Based on the observations and interviews, the researchers drafted a new version of the schema. 
Steps $2-4$ were repeated for versions 2 and 3 of the schema. As can be seen above, the data collection included observations and interviews, more specifically:

- Five observations of the assessors' use of the schema in relation to the dialogues with the young people. The purpose of the observations was to clarify the extent to which the assessors and the young people were able to understand and react relevantly to the formulations of respectively the competences and the three levels in the schema. Notes were taken throughout the observations the focus being on how the assessors and the young people explained and understood the competences and the competence levels. The length of each observation corresponded to the duration of each of the dialogues, i.e. $0.5-1$ hour.

- 29 semi-structured interviews have been conducted, the purpose of which was to learn about the assessors' experiences in assessing competences: How did the assessors understand the definitions of the competences respectively the three levels, and how did they - based on experiences with using the schema - develop the definitions of the social competences and the three levels? Were they able to distinguish the various competences in the schema? Which examples from the workplaces could be used to support the definition of the competences? How did the assessors explain and exemplify the content of the different competences to the young people? Related to the definition of the three levels: According to which criteria did the assessors refer the individual competences to a specific level?

The 29 interviews included interviews with:

- twelve representatives from the workplaces, i.e. four interviews within each of the three main vocational fields: technical VET, commercial VET, and social and health care VET.

- three representatives from the municipal guidance centres who were each interviewed three times in relation to a new draft of each of the three schemes.

- four teachers from the VET colleges who were interviewed twice in relation to the first and second drafts of the schema.

All interviews were based on the same set of questions, including that the informants should give examples that could illustrate their perceptions of the competences and their criteria for assessing the level of the competences. The interviews took 1-2 hours each, and central passages were transcribed.

The analysis of the data from the observations and interviews focused on how the assessors - based on experiences with using the schema - developed their understandings and definitions of the five social competences mentioned above. Likewise it was analysed how the assessors developed their understandings and definitions of the three levels for assessing the competences. It was analysed in which ways the assessors shared the same understandings or differed in their understandings (Cohen et al., 2011, p. 29). 


\section{Results}

The development of the definitions of the social competences has involved a division of each of the competences into sub-competences. The following findings are based on the experiences derived from developing these sub-competences.

The analysis of the empirical data focus on the following two issues:

- How do the assessors develop their understandings and definitions of the five social competences?

- How do the assessors develop their understandings and definitions of three levels for assessing the competences?

\subsection{The Development of the Assessors' Understandings and Definitions of Social Competences}

The development of the understandings and definitions of the social competences has led to two findings:

1. In order to be useful for assessing in specific contexts, the competences must be defined in relation to these contexts.

2. In order to be useful for assessing the definitions should not be too detailed.

Concerning the first finding, table 1 shows the development of the sub-competences for the competence 'communication'. The definitions in table 1 also show that the semantic focus in relation to the competences was altered during the development, becoming more specifically related to the purpose of the project, the purpose being to assess competences that are developed during workplace-based training and that are important for the young persons' development. The understanding of the competence 'communication' changed from focusing on the ability to talk and perform to the ability to receive and give feedback, feedback being considered by the assessors to be the core of the young person's communication with managers and colleagues. In this line of argumentation, 'perform personally in a correct and sure way' has been removed as interviews with the assessors showed that this sub-competence was not relevant for assessing the central elements of 'communication' in relation to the young people.

The dialogues with the assessors showed that the definitions should be idiomatic and everyday-like in order to be usable. Definitions that include actions were perceived as closer to the activities in the workplaces and it was easier to assess a competence when the assessors could visualize situations in which the young person might use it. This can be illustrated in the following example of the development of the definition of one of the sub-competences of 'responsibility'. In the first draft, the sub-competence was formulated in this way: 'Complete tasks in a satisfying manner.' In the final schema the corresponding formulation is: 'Complete tasks and do not leave a task half-done.' 'Not leave a task half-done' provides an interpretation of 'satisfying manner'. The adjective 
'satisfying' has been altered to a situation that is easier to visualize in the workplace, where completing tasks is first priority.

Table 1: Three versions of defining the sub-competences of 'communication'

\begin{tabular}{|c|c|c|c|}
\hline Competence & $\begin{array}{l}\text { First draft } \\
\text { of schema }\end{array}$ & $\begin{array}{l}\text { Second draft } \\
\text { of schema }\end{array}$ & $\begin{array}{l}\text { Final draft } \\
\text { of schema }\end{array}$ \\
\hline $\begin{array}{l}\text { Communica- } \\
\text { tion }\end{array}$ & $\begin{array}{l}\text { 1. Good at talking } \\
\text { with colleagues and } \\
\text { manager. } \\
\text { 2. Good at talking } \\
\text { with customers. } \\
\text { 3. Perform person- } \\
\text { ally in a correct and } \\
\text { sure way. }\end{array}$ & $\begin{array}{l}\text { 1. Communicate with } \\
\text { colleagues and man- } \\
\text { ager. } \\
\text { Explanation: is able } \\
\text { to talk with colleagues } \\
\text { and managers about } \\
\text { the work in a con- } \\
\text { structive way. Is able } \\
\text { to receive feedback on } \\
\text { job performance and } \\
\text { is able to pose ques- } \\
\text { tions and report back. } \\
\text { 2. Communicate with } \\
\text { users (customers / } \\
\text { participants). } \\
\text { Explanation: is able } \\
\text { to talk with users } \\
\text { about the work in } \\
\text { a constructive and } \\
\text { forthcoming manner. } \\
\text { Is able to receive com- } \\
\text { ments concerning job } \\
\text { performance and is } \\
\text { capable of answering } \\
\text { the users questions. }\end{array}$ & $\begin{array}{l}\text { 1. Is able to receive } \\
\text { feedback from man- } \\
\text { ager on ones job } \\
\text { performance and de- } \\
\text { monstrate the ability } \\
\text { to give feedback. } \\
\text { 2. Is able to receive } \\
\text { feedback from col- } \\
\text { leagues on ones job } \\
\text { performance and de- } \\
\text { monstrate the ability } \\
\text { to give feedback. } \\
3 \text {. Is able to listen to } \\
\text { and speak with users } \\
\text { (e.g. customers/ citi- } \\
\text { zens/children/parents) }\end{array}$ \\
\hline
\end{tabular}

The development towards formulations that are relatively close to work situations reflects the purpose of the assessments. It is important for the assessors to help the young person to visualize situations in which he or she might use or develop the competence: "As a supervisor you should help the young person to visualize situations that makes the young person understand the competence, i.e. examples and illustrations of the practice the young person is part of" (interview with a teacher). In the dialogues with the young people the competences should be contextualized in order to be useful. 
Another example of the significance of visualizing practice can be illustrated from the development of one of the sub-competences of 'communication' (table 1). The interviews with the assessors within the social and health care sector showed that they associated the phrase 'Good at talking with customers' with the sales programmes, and that they did not perceive it to be useful in relation to the social and health care sector. 'Communication' is a central and more complex competence within the social and health programmes than within the technical programmes. Consequently, the assessors within social and health care argued that the young people should be assessed on their ability to - for example - differentiate communication in relation to different kinds of users. Thus changing 'customers' in the first draft of the schema into 'users (customers/participants)' in the second draft did not meet the needs within the social and health care sector and was further differentiated as appears in the final schema: 'Listen to and speak with users (e.g. customers/citizens/children/parents)'.

The current context also influences the number of sub-competences. Looking at table 1 , this can be illustrated by comparing the three versions of the first sub-competence of 'communication'. The development from drafts 1 and 2 to the final schema shows a need for distinguishing between 'communicate with a manager' and 'communicate with colleagues', cf. table 1. Thus one of the sub-competences has been split into two. This amendment is a result of trying out the schema in the dialogues with the young people, the experience being that the young person, while good at communicating with colleagues, may not necessarily be good at communicating with the manager.

The second finding concerns the degree of detail in the definitions of the competences. Even though the results above indicate that it was important for the assessors to relate the competences to actions and performances in a workplace, the descriptions could also be too detailed to be useful across the different occupations, trades or industries. A comparison of the three versions of the sub-competences in table 1 shows that in the second draft particular emphasis has been placed on elaborating, i.e. 'explaining' the sub-competences. In the second draft the sub-competences, such as 'Communicate with colleagues and manager', were explained in relatively more detail than in the first draft. In the second draft the ambition was to strengthen the validity and reliability of the assessment by including more aspects of the communication with the managers: 'constructive way', 'feedback' and the ability to 'pose questions' and 'report back'. The idea was that these elaborations would support the assessment process, guiding the assessors to look for the specific characteristics of communication.

However, the relatively detailed explanations turned out not to have the expected effect. The explanations did not lead to a greater clarification of the competences and consequently did not improve the assessors' mutual understanding of the competences, nor their ability to assess them. According to the assessors, the explanations complicated the assessment, as more words were introduced. Too many words made the definitions unwieldy. Furthermore, some of the explanations referred too much to specific trades or industries meaning that the assessors had to translate the explanations to their "own" trades or industries. A comparison of the second draft and the final schema shows that a reduction of words was needed and only the concept 'feedback' survived.

Based on the findings, the general lesson to be learnt from developing the definitions 
of the competences is that the definitions move from being general and non-contextual to become more specific and contextualized. However, the descriptions should not be so detailed and contextualized that they cannot be translated to different trades, industries, workplaces etc.

\subsection{The Development of the Assessors' Understandings and Definitions of Three Levels for Assessing the Competences}

As mentioned above, the development of the young persons' competences took place in three dialogue meetings during the six months of workplace training. Drafting a useful scale for describing this development presented us with two issues: the number of levels and the wording of these levels.

At the first meeting with the assessors it was decided that the competences should be assessed at three levels. A three level scale makes completing the schema manageable while allowing assessors to indicate development, whether to the better or to the worse. The wordings of the levels in the scale have been based on the following three criteria:

1. They should be positive.

2. They should show a progression.

3. They should be idiomatic.

The development of the scale has resulted in the following two findings:

The first finding is that the scale depends on the standards for the assessment. A distinction between objective and subjective standards turned out to be relevant in the project. Objective standard means that the person is assessed in relation to external and predefined standards; e.g., standards formulated in the curricula for the VET programmes. Subjective standard means that the person is assessed in relation to his or her previous performances.

Table 2 shows two of the scales developed in the project illustrating the objective standard and the subjective standard respectively. The objective standard was based on what could be expected from a 'normal' worker in this occupation or in the actual workplace. The subjective standard was based on assessment of the how well the individual young person performed over time compared with the initial level.

Table 2: Scale for assessment based on, respectively, objective and subjective standards

\begin{tabular}{llll}
\hline Assessment based on: & Level $\mathbf{1}$ & Level $\mathbf{2}$ & Level $\mathbf{3}$ \\
\hline Objective standard & Okay & Good & Very good \\
\hline Subjective standard & Beginner & Trained & Experienced \\
\hline
\end{tabular}


The change from objective standards to subjective standards was based on the results from the interviews with the assessors, in which the general view was that the purpose of filling in the schema was to encourage the young person: "Perhaps it is not so important at which competence level the young people are; the important thing is that they have progressed" (teacher from a VET college); "the schema has been proven to motivate the young people; they experience that they are progressing, and they also realize if they have to improve, e.g. if they have slackened in terms of meeting on time" (representative from a municipal guidance centre); "when the young person studies the ticks in the schema, it strengthens her self-confidence" (employer). The function of the schema has changed from being a tool for assessing and awarding credits to being a tool for guidance: The schema is used for guidance, e.g. "you (addressing the young person) ought to develop your ability to take initiative to accomplish a work task, e.g. initiate play" (representative from a municipal guidance centre about a young person training in a kindergarten).

The purpose being to motivate the young people, it was important that the assessors could tick off one of the levels in the scale. The interviews and observations showed that the wordings at level 1 sometimes meant that the young person could not even qualify for a tick at the lowest level. Thus, in relation to the competence 'To be able to meet on time', some of the young people could not be characterized as 'Okay', because they had not yet managed to turn up at the workplace on time. The formulation 'Beginner' proved to be the most acceptable, the argument being that a person can always be defined as a beginner as this does not indicate whether he or she can actually perform.

The second finding is that the assessors assess the level of social competences in relation to specific work tasks or work situations. One of the aims in the interviews was to make the assessors explain their principles for referring a person to a specific level. Below, an assessor's example deals with operationalizing the three levels of the competence 'independence'.

The example shows that the competence is assessed in relation to accomplishing work tasks or performing in situations in the workplace, in this case a kindergarten:

- Beginner: The young person is able to provide food for the children and is able to handle simple conflicts, e.g.: 'please remove your feet from the table'!

- Trained: The young person is seated among the quieter children, providing food for the children while at the same time reacting to various situations at the table, such as table manners, whether the children drink and eat sufficiently, conflicts among the children etc.

- Experienced: the young person can accomplish the tasks that are included in a meal, i.e. providing food for the children, attending to the children's table manners, taking care that the children drink and eat sufficiently, and solving conflicts including all children within the group.

By taking an example from a situation in the kindergarten, the assessor shows that the situation can involve few or rather many tasks, and that the tasks can be more or less 
complicated. Thus the competence 'act responsibly' can be graded according to the number and type of tasks in a typical situation.

Summing up, the development of the scale has shown that the wordings of the levels depend on the purpose of the assessment. In this case the purpose was to show the young person that he or she is progressing. This resulted in a change from objective standards to subjective standards. Furthermore, the assessment of the level of social competences is made in relation to accomplishing specific tasks or performing in specific situations within specific workplaces, occupations, trades or industries. Therefore, the levels are not general; rather they should be understood in relation to specific contexts.

\section{Discussion and Limitations}

Juxtaposing the results from developing the schema with results from other studies about assessment of social competences, the following limitations and issues for discussion should be raised.

The first issue is to which degree social competences are context-bound: is it possible to find general and context-independent dimensions in these competences and in the assessment procedures? Or should we conclude that "... what is considered to be socially competent depends on the context"? (Dam \& Volman, 2007, p. 294). The development of the schema for assessing social competences has shown that these competences are closely related to the specific person's ability to act in a specific context, meaning that the assessment of a person's social competences will most easily be conducted, or can perhaps only be conducted, in relation to the specific context. Our data shows that the assessors based their definitions of the levels of the competences on specific examples from the work situations they encountered. In the examples of the competence 'act independently', the assessors related the general competence to a specific task or situation within the occupational field or within the current workplace. The context related understanding of the schema limits the possibility of using the schema to assess social competences in general. However, the data also shows that different assessors from different occupational fields were all able to understand and use the definition of for example 'act independently'. The development of the schema illustrates that it is important that general terms such as 'users' are exemplified in relation to the specific occupation as 'customers, citizens, children, parents'. However, with these adjustments it was possible to construct an assessment instrument - in this case a schema - that allows assessors to assess social competences across different vocational sectors.

The second issue concerns the degree of elaboration of the competences in the schema. In the second version of the schema the sub-competences were formulated in a relatively lengthy manner, including explanations. These elaborations were meant to contextualize the competences by describing typical activities in the workplace and in that way guide the assessor to the elements of practice that they should take into consideration in their assessments. However, the elaborations meant that the assessors actually had too many elements to take into consideration, complicating the assessment. Discussing experiences with competence-based assessment in a vocational setting, Alison Wolf highlights the 
same issue. She cautions against overly specialized descriptions of the competences and too many detailed requirements (Wolf, 2001). David Pepper, discussing how to assess key competences, likewise concludes: "...the challenge is specifying key competences in sufficient detail to plan and assess learning - but not with so much prescription that the process of developing competences is reduced to a series of procedural tasks..." (Pepper, 2011, p. 341).

A report from CEDEFOP highlights the issue in relation to assessment in small companies: "Several interviewed experts note that often in small-sized companies it does not pay to use sophisticated and expensive assessment systems. Assessment procedures should not be overelaborated and too complex as the additional cost would outweigh the benefit" (CEDEFOP, 2014, p. 69).

A literature review on the assessment of key competences also cautions that " overspecification of learning outcomes should be avoided" (European Commission, 2012). Based on the findings from our and other studies, we conclude that written elaborations of the sub-competences do not improve the quality of the assessment; on the contrary.

The third issue concerns the assessors' qualifications. The idea was to develop a schema that practitioners can understand and use without instruction or training. However, a number of studies emphasize the need to train the assessors (CEDEFOP, 2015, p. 32; European Commission, 2014, p. 42). In the current project the assessors have not been trained as assessors. Even so, they were able to understand and use the schema. The most likely explanation is that the assessors were actually trained through their participation in developing the schema, which included interviews with them about their procedures for assessment and their perceptions of the definitions of the competences. If one can argue that the assessors were trained, albeit informally, and if the assessment of in particular social competences is closely linked to contexts with which these assessors are familiar, further research is needed in order to conclude whether the schema can be understood and used without further introduction or training.

Finally, the study has been accomplished as a research project, meaning that 'its claim to validity lies in the dialectic relationships among the epistemological frames of the participants' (McTaggart, 2014, p. 463). The results depend on whether the researchers and the practical participants share a sufficient insight in the assessment process. It could be argued that a limitation of the study is that the findings are too closely related to the assessors 'epistemological frames'.

\section{Conclusion and Perspectives}

Much of the individual's total competence is obtained outside the educational system in informal leaning contexts. Currently there is focus on the acquisition of competences and learning in workplaces and an increasing awareness of the importance of social competences in relation to workplace-based learning and vocational education and training. This includes a focus on the assessment of these competences and consequently on developing assessment methods. Based on the experiences from developing a schema for assessing social competences, the following conclusions can be drawn. 
The understanding of competence and the assessment of these competences is related to the context in which the competence has been developed. Even generic competences like social competences are related to the context in which the competences should be used. A person is not socially competent at a general level; a person is more or less socially competent in relation to a specific context.

Likewise, assessors operationalize the levels of competence by referring to specific tasks or situations in the workplace. The assessors assessed the levels of the identified social competences, not at a general level, but in relation to the way the person performed and found solutions to work-related problems.

The development of the schema reflects that the assessors' understanding and assessment of the competences depends on the current context. Thus the definitions of the competences have developed from being general and context-independent to being context-dependent and more closely connected to the tasks and situations in the workplaces. In the final version of the schema, the definitions reflect that the important activities in a workplace concern the accomplishment of work tasks and performing in work situations. Furthermore, the definitions have developed to reflect the needs of the target group, i.e. young people who, through work-based training, should become more motivated to enrol in a VET programme. The definitions of the competences should enable the young person to recognize or visualize the situations in which the competences are relevant, and the levels should be adequate for assessing the young person against his or her individual level of performance. However, the definitions should not be too detailed and lengthy, as too many details blur and confuse the focus of the assessment. In the schema, a balance has been sought to secure context-specific definitions that are not too detailed. The litmus test is whether assessors who have not participated in the development of the schema are able to use the schema without previous training.

Assessment of competences is an integral part of the individual's development of competences, having an educational function. The results of the assessment were used to guide dialogues with the young people. These dialogues contain a systematic review of what has been learned and what could be improved and have a motivational effect on the young person.

In a further perspective, the study raises three issues:

- Assessment of social competences in a workplace setting provides opportunities for guidance to improve the learning process.

- The process of developing tools for assessing social competences clarifies the specific content of these competences in a particular context.

- Through developing methods for assessing social competences, the importance of these competences is highlighted. 


\section{References}

Aarkrog, V., \& Wahlgren, B. (2015). Assessment of Prior Learning in Adult Vocational Education and Training. International Journal for Research in Vocational Education and Training, 2(1), 39-38.

Alqiawi, D. A., \& Ezzeldin, S. (2015). A Suggested Model for Developing and Assessmment Competence of Prospective Teachers in Faculties of Education World Journal of Education, 5(6), 65-73.

Bezanilla, M., Arranz, S., Rayón, A., Rubio, I., Menchaca, I., Guennaga, M., \& Aguilar, E. (2014). A proposal for generic competence assessment in a serious game. New Approaches in Educational Research, 3(1), 42-51.

Boud, D., \& Falchikov, N. (Eds.). (2007). Rethinking Assessment in Higher Edacation. New York: Routledge.

CEDEFOP. (2014). Use of validation by enterprises for human resource and career development purposes. Retrieved from: http://www.cedefop.europa.eu/en/ publicationsand-resources/publications/3065

CEDEFOP. (2015). European guidelines for validating non-formal and informal learning. Retrieved from: http://www.cedefop.europa.eu/en/publications-and-resources/publications/3073

Cohen, L., Manion, L., \& Morrison, K. (2011). Research Methods in Education. London and New York: Routledge.

Dam, G., \& Volman, M. (2007). Education for Adulthood or for Citizenship: Social competence as an educational goal. European Journal of Education, 42(2), 281298.

Denham, S. A. (2015). Assessment of SEL in Educational Contexts. In J. A. Durlak, C. E. Domitrovich, R. P. Weissberg, T. P. Gullotta (Eds.), Handbook of Social and Emotional Learning. New York and London: The Guildford Press, 285-300.

Dumitriu, C., Dumitriu, G., \& Timofti, I. (2014). Teachers' professional development and career advancement. Limitations of current model of professional competences assessment. Procedia - Social and Behavioral Sciences, 116, 864-868.

Eccleston, K. (2010). Transforming formative assessment in lifelong learning. McGraw Hill and Open University Press.

Ekkelenkamp, V. E., Kock, A. D., de Man, R. A., \& Kuipers, E. J. (2016). Training and competence assessment in GL endoscopy: a systematic review. Gut, 65, 607-615.

Ellström, P.-E., \& Koch, H. (2008). Competence Development in the Workplace: Concepts, Strategies and Effects. Asia Pacific Education Review, 9 (1), 5-20.

Eraut, M. (1998). Concepts of competence. Journal of Interprofessional Care, 12(2), 127-139.

European Commission. (2012). Education and Training 2020 Work Programme - Thematic Working Group 'Assessment of Key Competences'. Retrieved from: http://ec.europa.eu/education/policy/school/doc/keyreview_en.pdf

European Commission. (2014). European inventory on validation of non-formal and informal learning 2014. Retrieved from: https://cumulus.cedefop.europa.eu/files/vete lib/2014/87244.pdf 
European Communities. (2007). Key Competences for Lifelong Learning - European Reference Framework. Retrieved from: http://eur-lex.europa.eu/legal-content/EN/ TXT/?uri=uriserv:c11090

Frey, A., Balzer, L., \& Ruppert, J.-J. (2014). Transferable competences of young people with a high dropout risk in vocational training in Germany International Journal for Educational and Vocational Guidance, 14(1), 119-134.

Garside, J. R., \& Nhemachena, J. Z. Z. (2013). A concept analysis of competence and its transition in nursing. Nurse Education Today, 33, 541-545.

Halttunen, T., Koivisto, M., \& Billett, S. (Eds.). (2014). Promoting, Assessing, Recognizing and Certifying Lifelong Learning - International Perspectives and Practices. Dordrecht Heidelberg New York London: Springer.

Harris, J., Breier, M., \& Wihak, C. (Eds.). (2011). Researching the Recognition of Prior Learning - International perspectives. Leicester: International Institute of Adult Continuing Education (niace).

Kanfer, R., \& Ackerman, P. L. (2005). Work Competence - A Person-Oriented Perspective. In A. J. Elliot \& C. S. Dweck (Eds.), Handbook of Competence and Motivation. New York and London: The Guilford Press, 336-353.

Klenowski, V., \& Wyatt-Smith, C. (2014). Assessment for Education. Standards, Judgement and Moderation. London: SAGE.

Le Deist, F. D., \& Winterton, J. (2007). What Is Competence? Human Resource Development International, 8(1), 27-46.

McTaggart, R. (2014). Evolving Ethics of Educational Research. In A. D. Reid, E. P. Hart \& M. A. Peters (Eds.), A Companion to Research in Education. Dordrecht, Heidelberg, New York, London: Springer, 457-469.

Mulder, M. (2001). Competence development - some background thoughts. The Journal of Agricultural Education and Extension, 7(4), 147-158.

Mulder, M., Gulikers, J., Biemans, H., \& Wesselink, R. (2009). The new competence concept in higher education: error or enrichment? Journal of European industrial Training, 33(8/9), 755-770.

Mulder, M., Weigel, T., \& Collins, K. (2007). The concept of competence in the development of vocational education and training in selected EU member states: a critical analysis. Journal of Vocational Education and Training, 59(1), 67-88.

OECD (2005). The Definition and Selection of Key Competencies. Executive Summary. Retrieved from: http://www.oecd.org/pisa/35070367.pdf

Papastephanou, M. (2014). Theory, Practice and the Philosophy of Educational Action Research in New Light. In A. D. Reid, E. P. Hart \& M. A. Peters (Eds.), A Companion to Research in Education. Dordrecht, Heidelberg, New York, London: Springer.

Pepper, D. (2011). Assessing Key Competences across the Curriculum - and Europe. European Journal of Education, 46(3), 335-355.

Räisänen, A., \& Räkköläinen, M. (2014). Assessment of learning outcomes in Finnish vocational education and training. Assessment in Education: Principles, Policy \& Practice, 21(1), 109-124. 
Schirmer, J. M., Mauksch, L., Lang, F., Marvel, K. M., Zoppi, K., Lang, F., Epstein, R. M., Brock, D., Pryzbylski, M. (2005). Assessing Communication Competences: A Review of Current Tools. Medical Student Education, 37(3), 184-192.

Schön, D. A. (1983). The Reflective Practitioner. How Professionals Think in Action. New York: Basic Books.

Undervisnings Ministeriet. (2015). http://www.uvm.dk/Uddannelser/ Erhvervsuddannelser/Lovgivning-og-reform/Uddannelsesbekendtgoerelser

Walklin, L. (1991). The Assessment of Performance and Competence. Cheltenham, England: Stanley Thornes.

Wolf, A. (2001). Competence-Based Assessment. In J. Raven \& J. Stephenson (Eds.), Competence in the Learning Society (pp. 453-466). New York: Peter Lang.

Yanhua, C., \& Watson, R. (2011). A review of clinical competence assessment in nursing. Nurse Education Today, 31, 832-836.

Zegwaard, K., Coll, R., \& Hodges, D. (2003). Assessment of Workplace Learning: A Framework. Asia-Pacific Journal of Cooperative Education, 2003(1), 9-18. 


\section{Bibliographical Note}

Dr Vibe Aarkrog PhD is associate professor in VET pedagogy at the Department of Education, Aarhus University, Denmark. Her research focuses on the interrelation between the school-based and workplace-based parts of dual programs and on transfer of training from school to workplace and vice versa.

Dr Bjarne Wahlgren PhD is professor at the Department of Education at Aarhus University,Denmark, and director for The National Centre of Competence Development. His research focuses on transfer of training, assessment of competences, dropout and teacher training in adult and vocational education. 